\title{
Fluorophore Appended Saccharide Cyclophane: Self-Association, Fluorescent Properties, Heterodimers with Cyclodextrins, and Cross-Linking Behavior with Peanut Agglutinin of Dansyl-Modified Saccharide Cyclophane
}

\author{
Osamu Hayashida * and Itaru Hamachi \\ Institute for Materials Chemistry and Engineering, Kyushu University, Hakozaki, Higashi- \\ ku, Fukuoka 812-8581, Japan
}

Table of Contents

General

${ }^{1} \mathrm{H}$ NMR spectrum of compound $\mathbf{1}$

${ }^{13} \mathrm{C}$ NMR spectrum of compound $\mathbf{1}$

${ }^{1} \mathrm{H}$ NMR spectrum of compound 2

${ }^{13} \mathrm{C}$ NMR spectrum of compound $\mathbf{2}$

${ }^{1} \mathrm{H}$ NMR spectrum of compound $\mathbf{3}$

${ }^{13} \mathrm{C}$ NMR spectrum of compound $\mathbf{3}$

${ }^{1} \mathrm{H}$ NMR spectrum of compound 4

${ }^{1} \mathrm{H}$ NMR spectrum of compound $\mathbf{5}$

${ }^{13} \mathrm{C}$ NMR spectrum of compound $\mathbf{5}$

${ }^{1} \mathrm{H}$ NMR spectrum of compound $\mathbf{6}$

${ }^{13} \mathrm{C}$ NMR spectrum of compound 6
Page:

S2

S3

S4

S5

S6

S7

S8

S9

S10

S11

$\mathrm{S} 12$

S13 
General. Fluorescence spectra were recorded by excitation at 340, 326, 365, and 340 $\mathrm{nm}$ for dansyl-SE, TNS, ANS, and 1, respectively. 2,11,20-1,6,20,25Tetraaza[6.1.6.1] paracyclophane (4) was prepared after a method reported previously. ${ }^{21}$ 

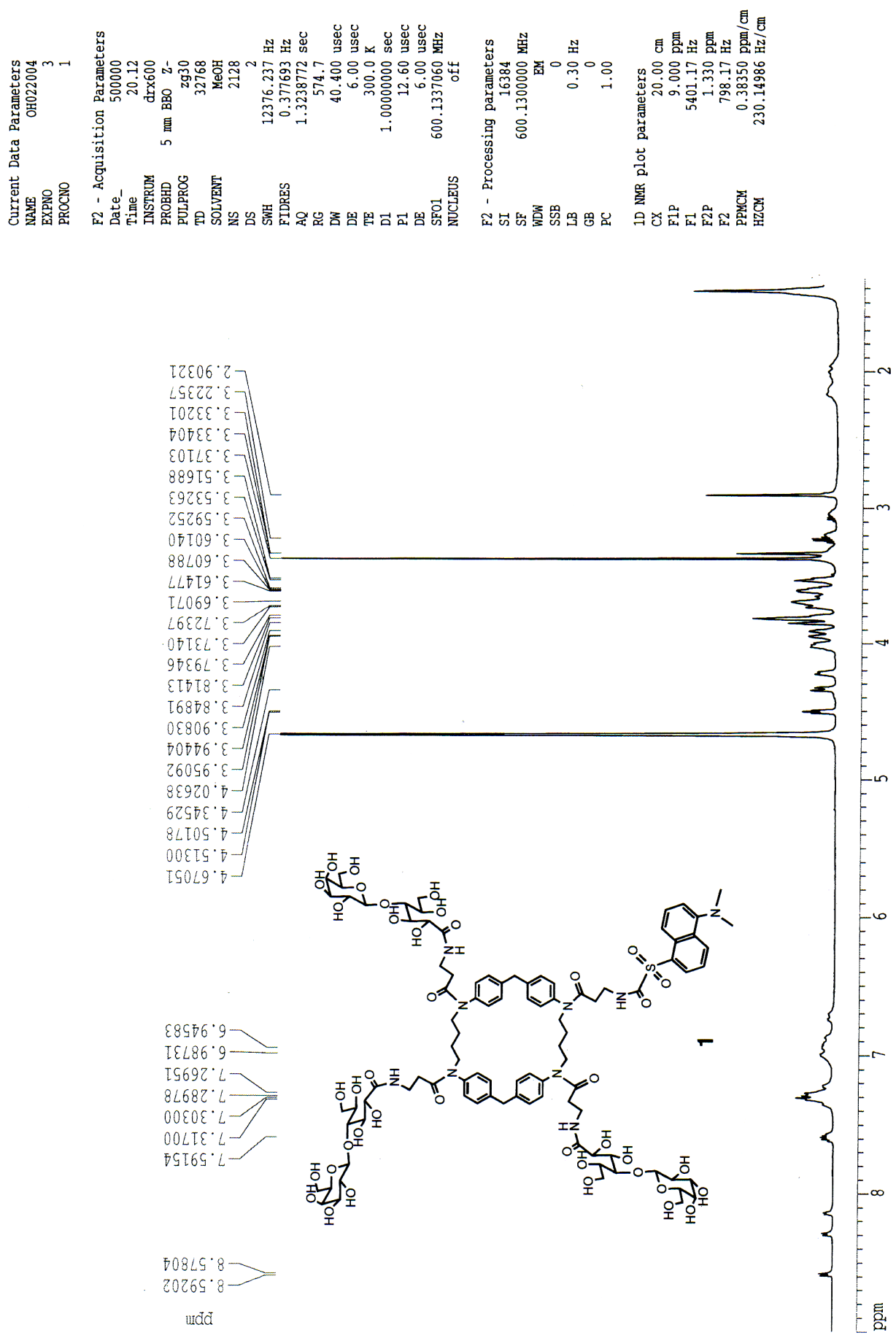

Figure 1. ${ }^{1} \mathrm{H}$ NMR spectrum of compound 1 

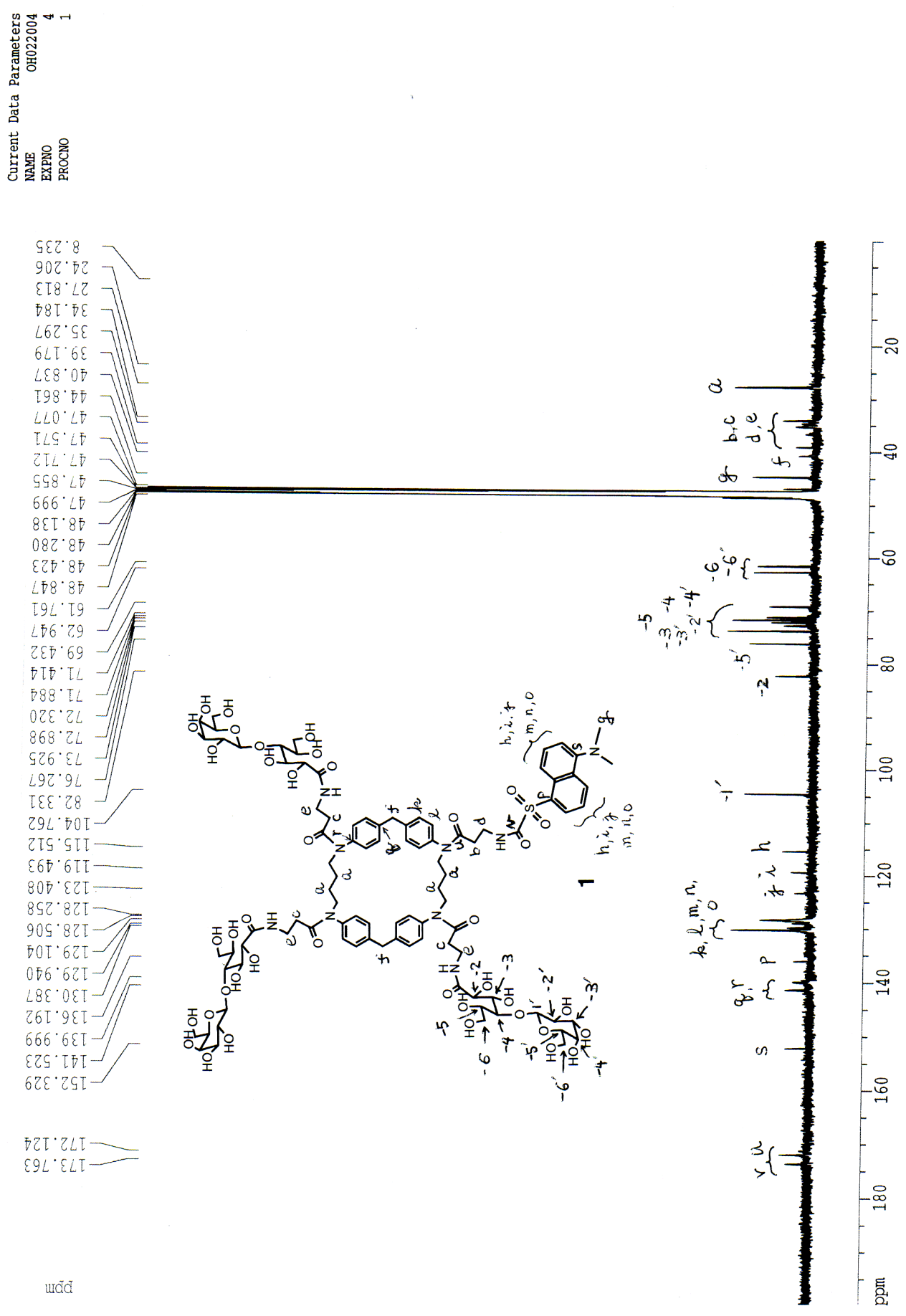

Figure 2. ${ }^{13} \mathrm{C}$ NMR spectrum of compound $\mathbf{1}$ 

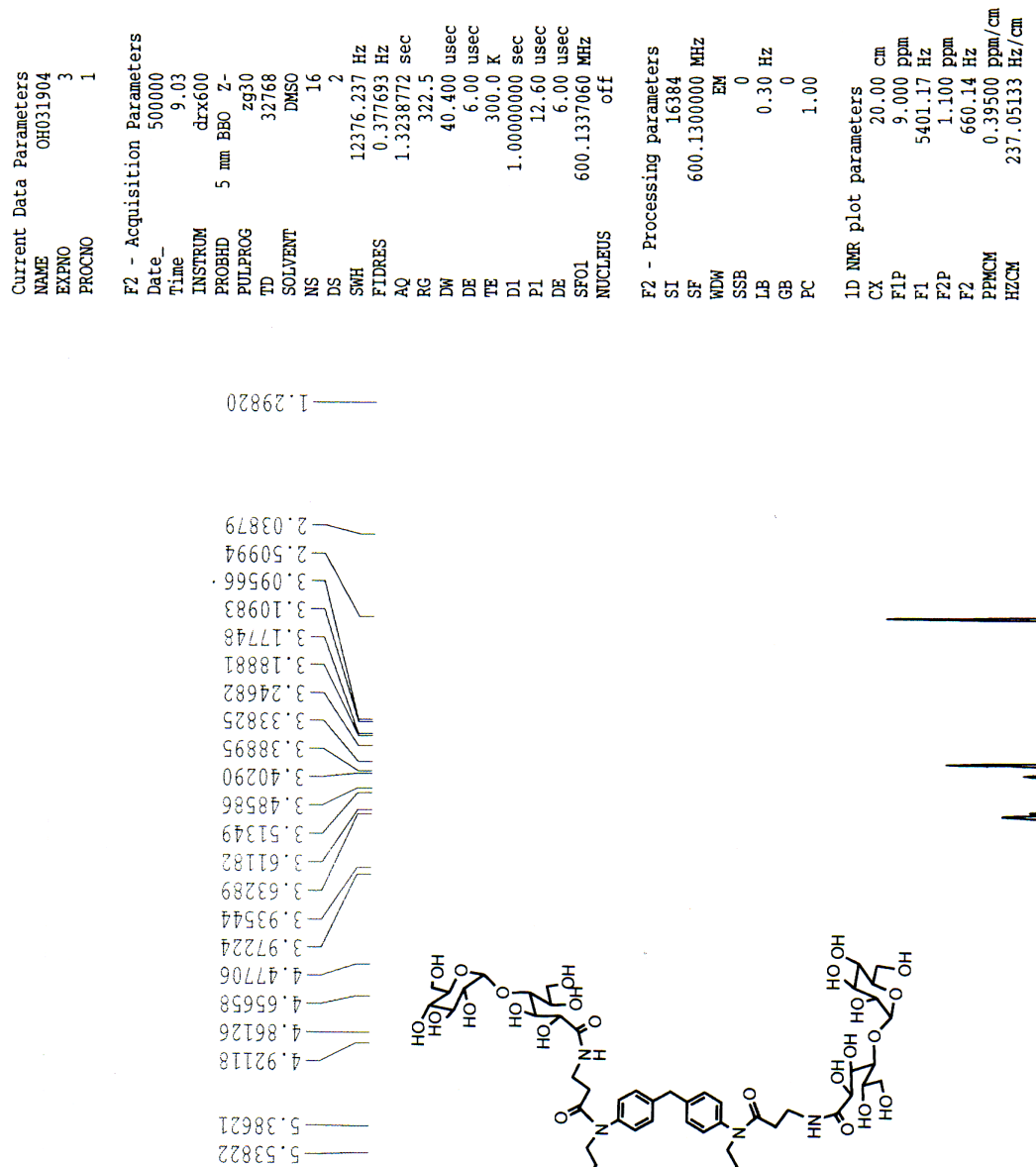

$S 7260^{\circ} L$

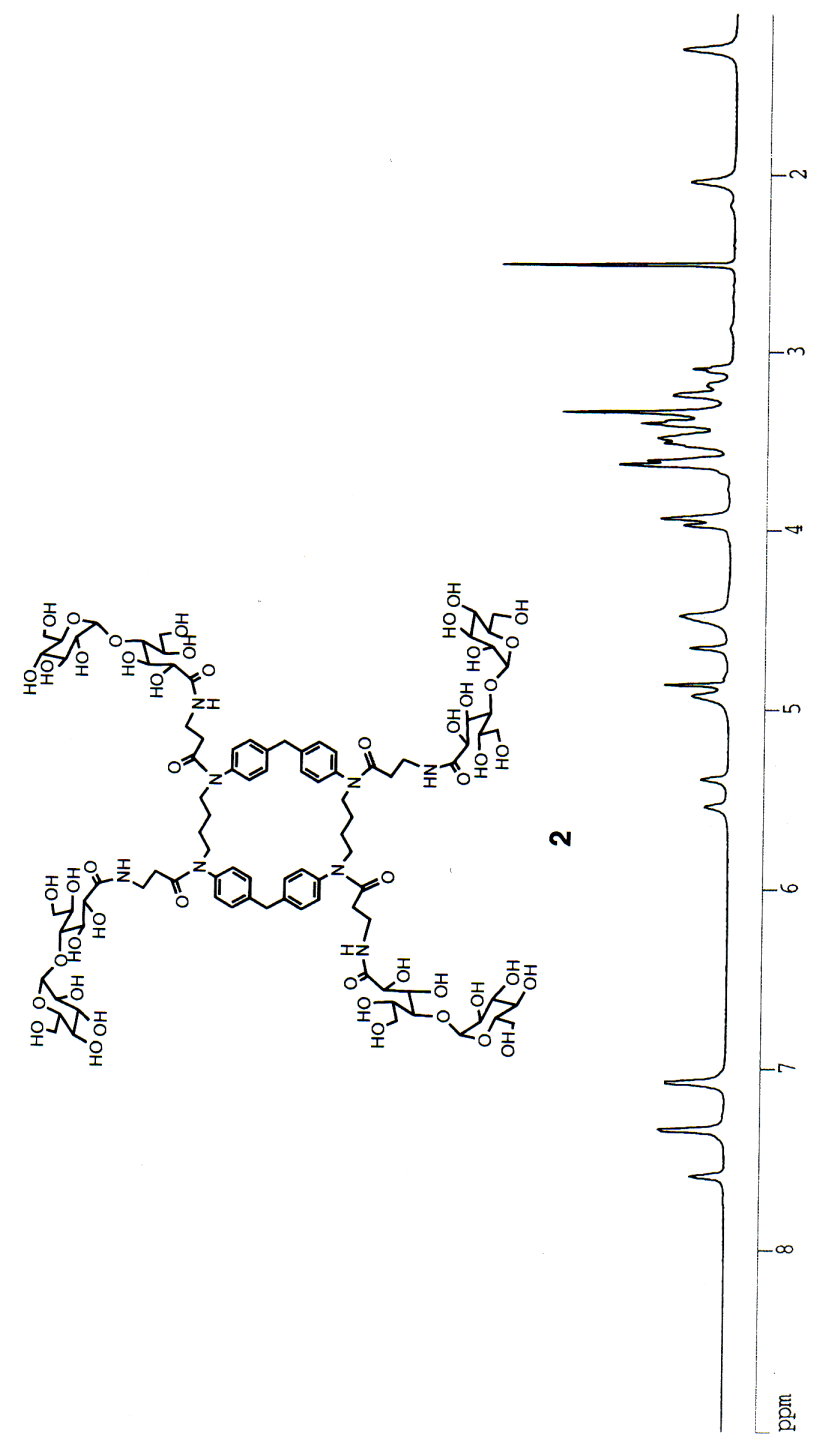

ร9Gรह $L \longrightarrow$

60SE $\varepsilon^{\circ} L$

$72565^{\circ} \mathrm{L}$

udd

Figure 3. ${ }^{1} \mathrm{H}$ NMR spectrum of compound 2 

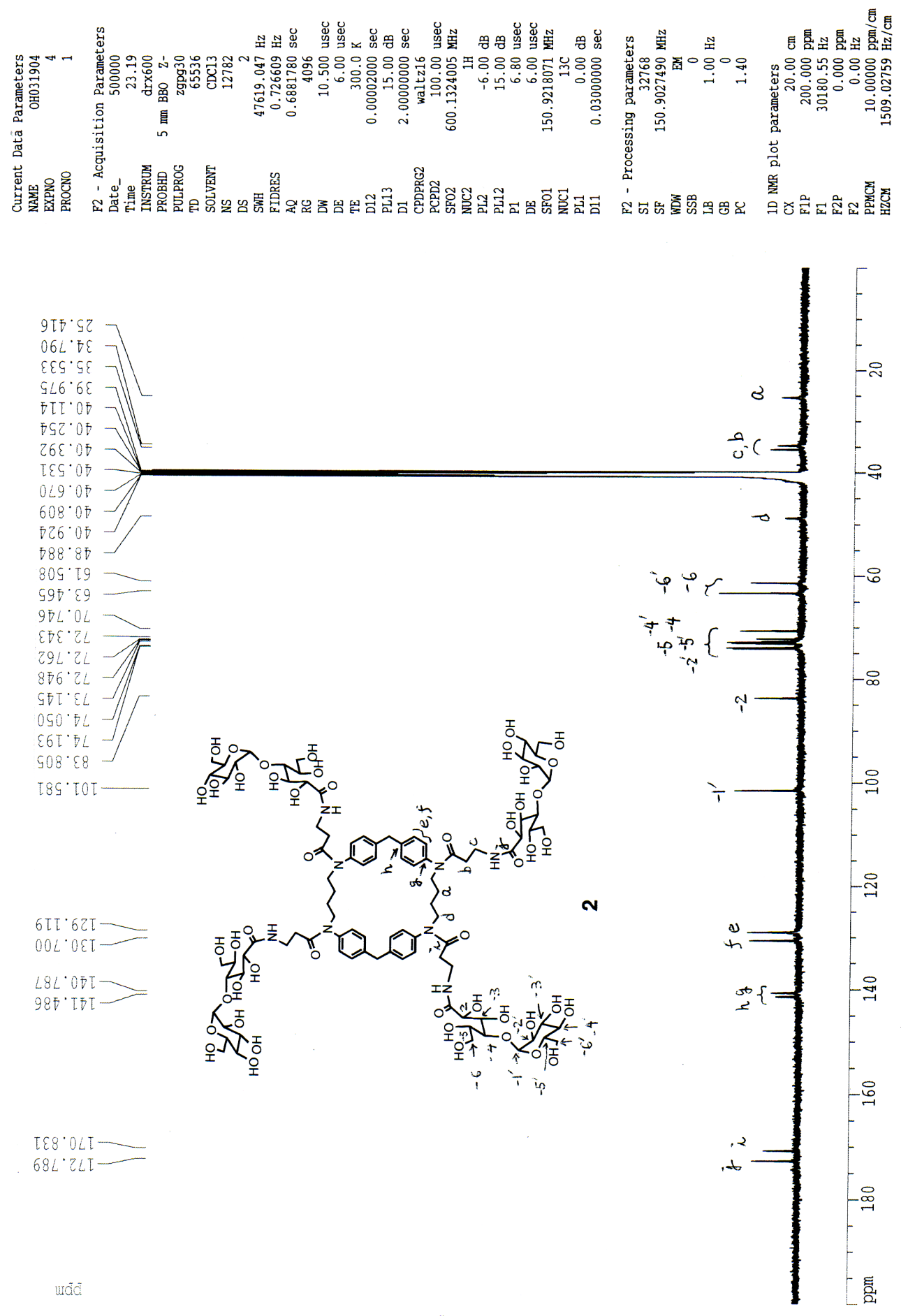

Figure 4. ${ }^{13} \mathrm{C}$ NMR spectrum of compound 2 

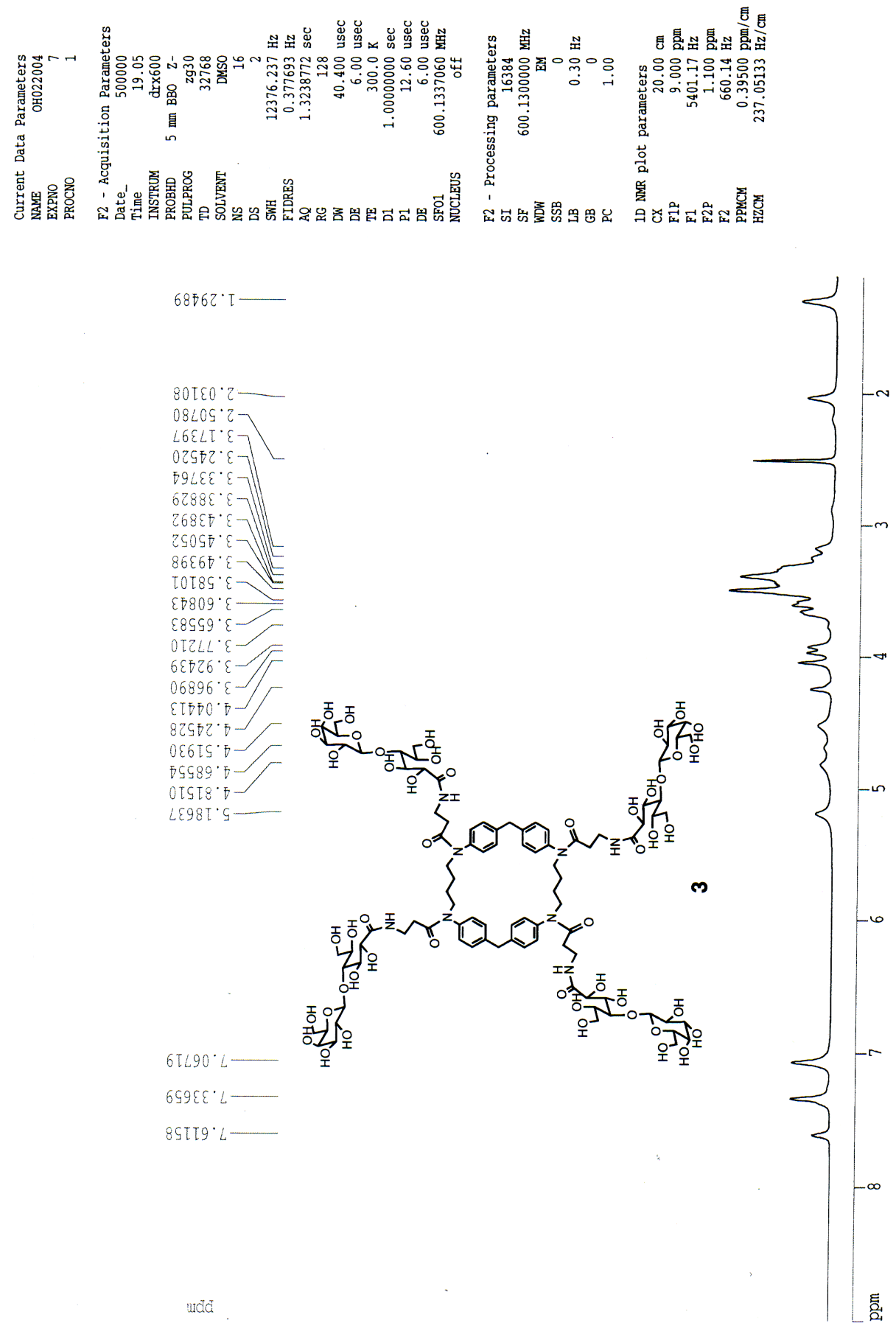

Figure 5. ${ }^{1} \mathrm{H}$ NMR spectrum of compound $\mathbf{3}$ 

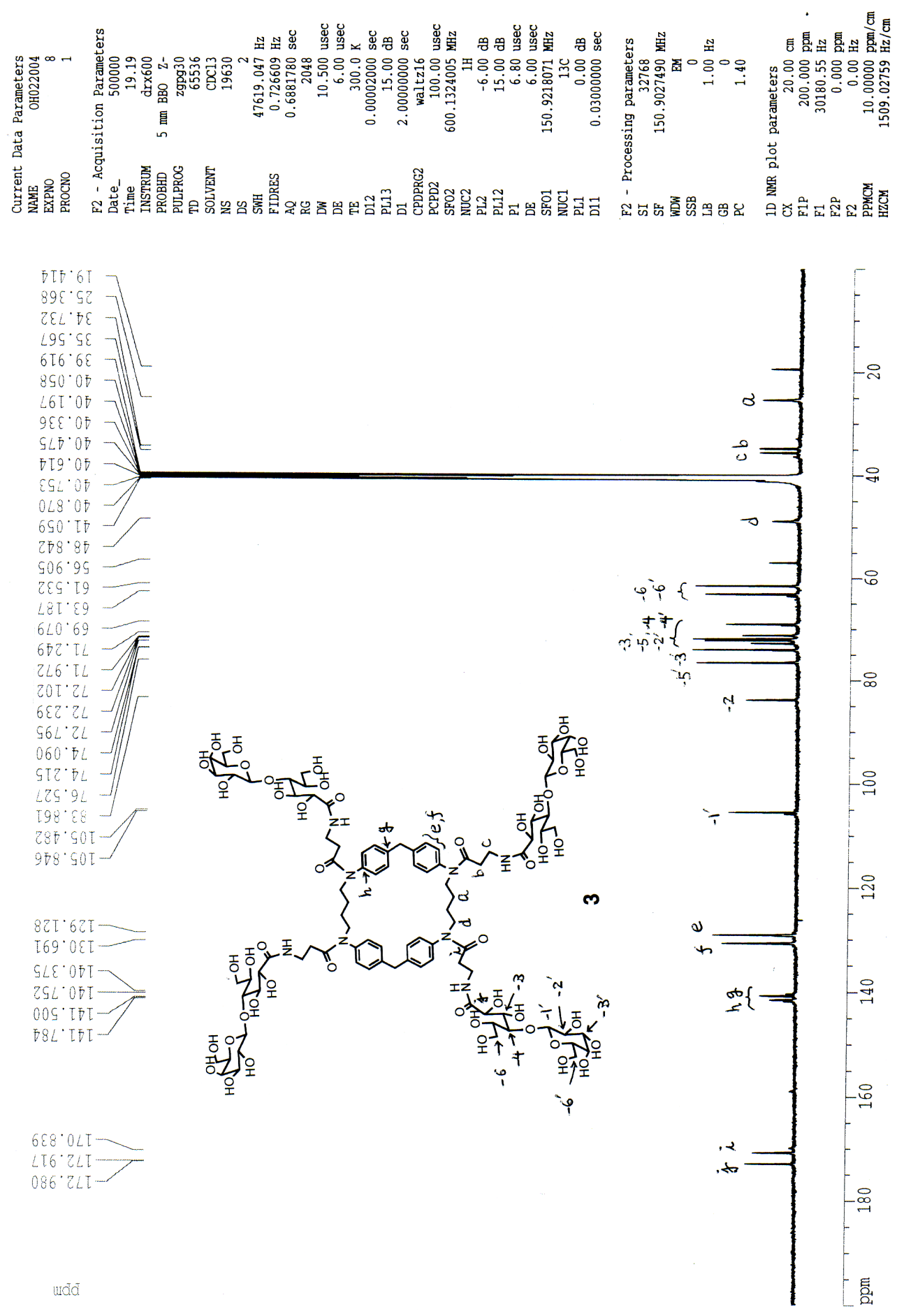

Figure 6. ${ }^{13} \mathrm{C}$ NMR spectrum of compound 3 


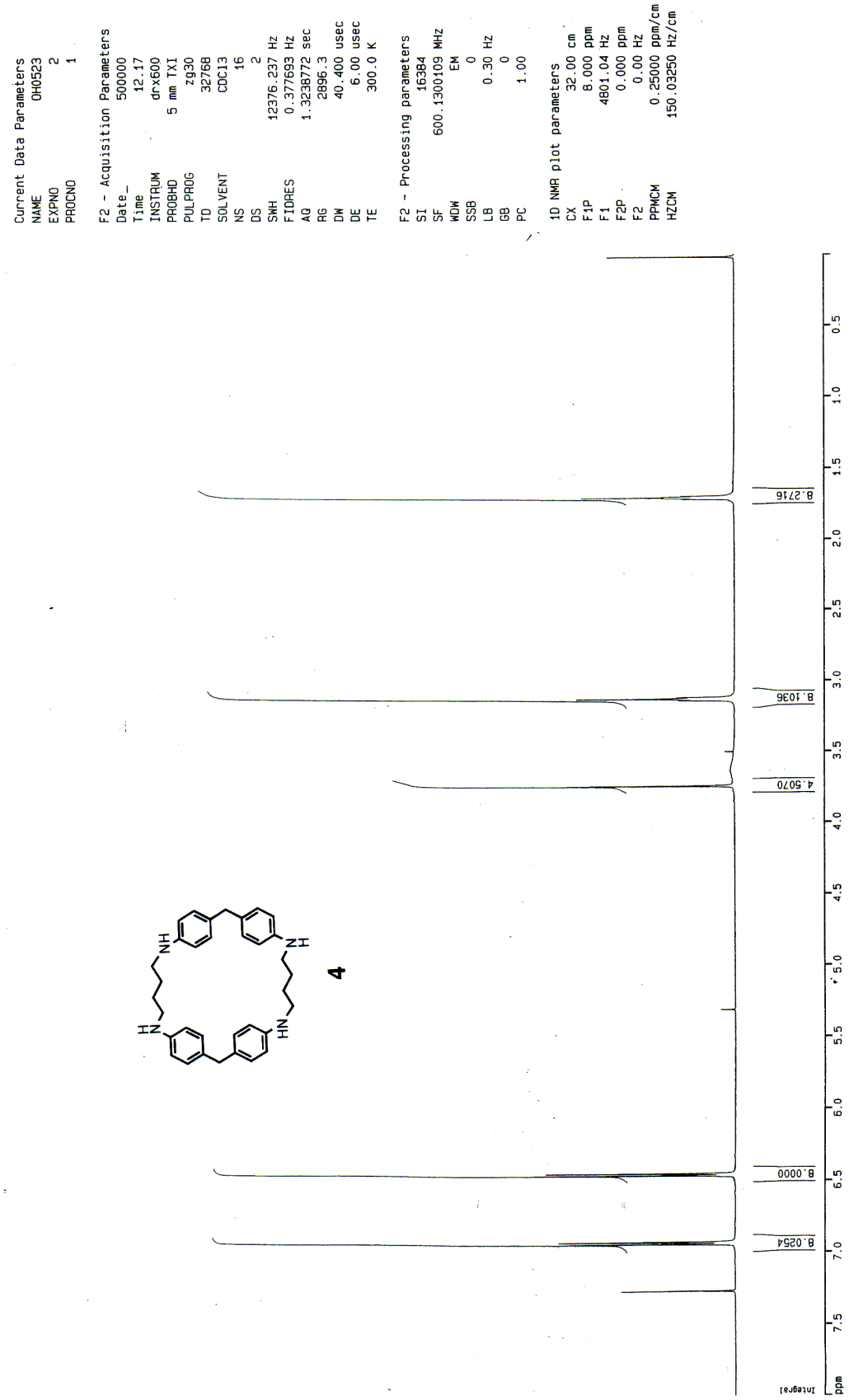

Figure 7. ${ }^{1} \mathrm{H}$ NMR spectrum of compound 4 

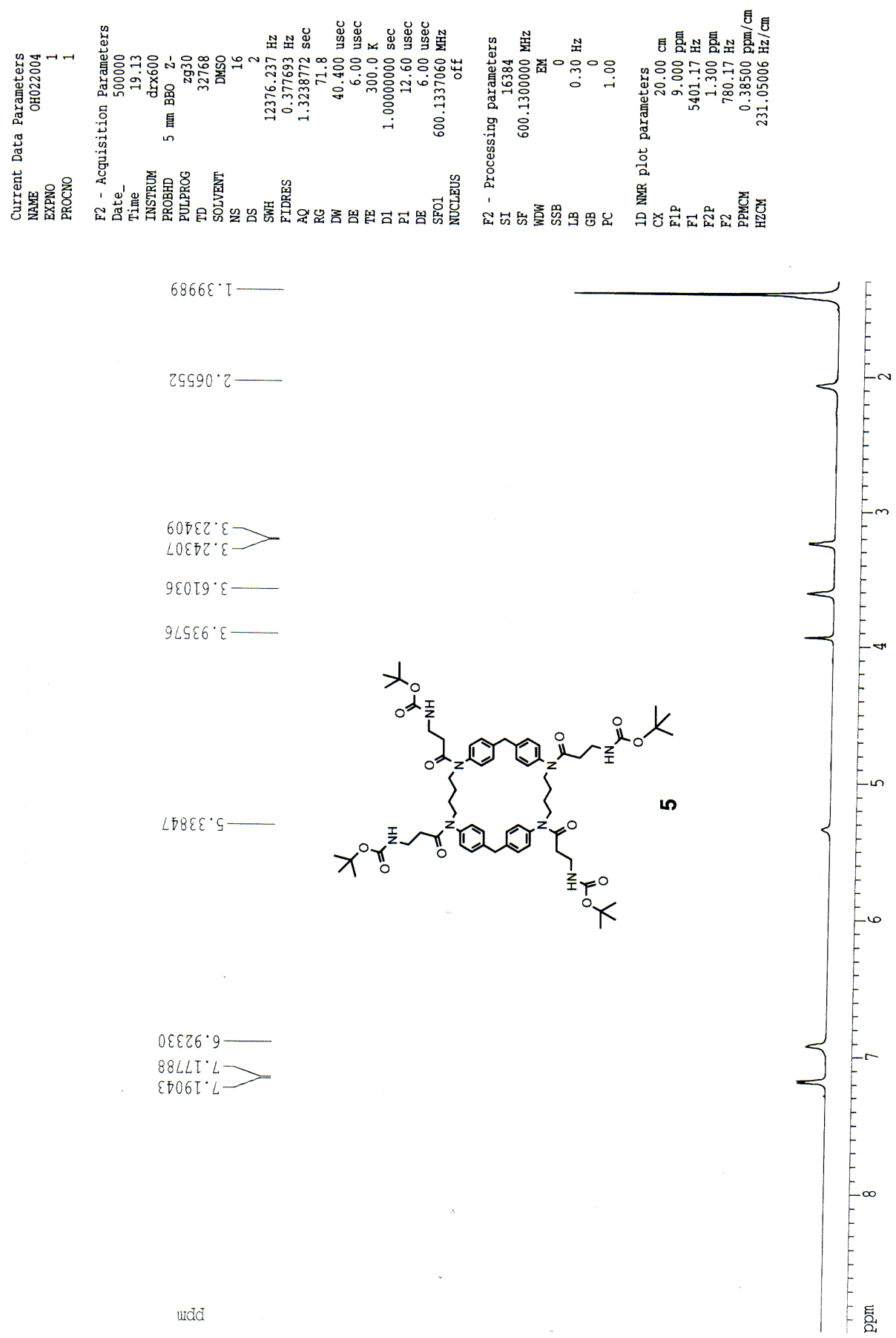

Figure 8. ${ }^{1} \mathrm{H}$ NMR spectrum of compound 5 

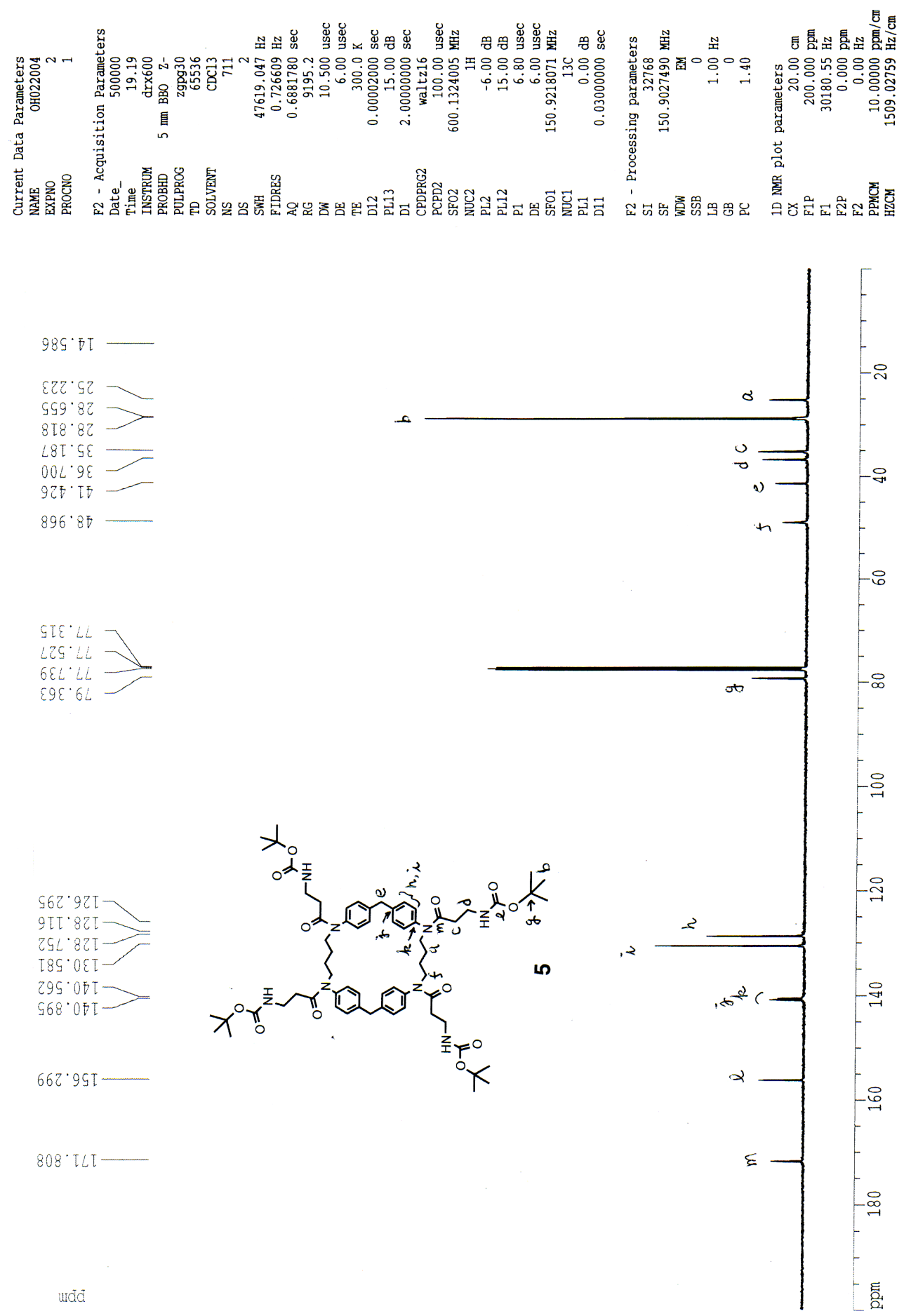

Figure 9. ${ }^{13} \mathrm{C}$ NMR spectrum of compound 5 

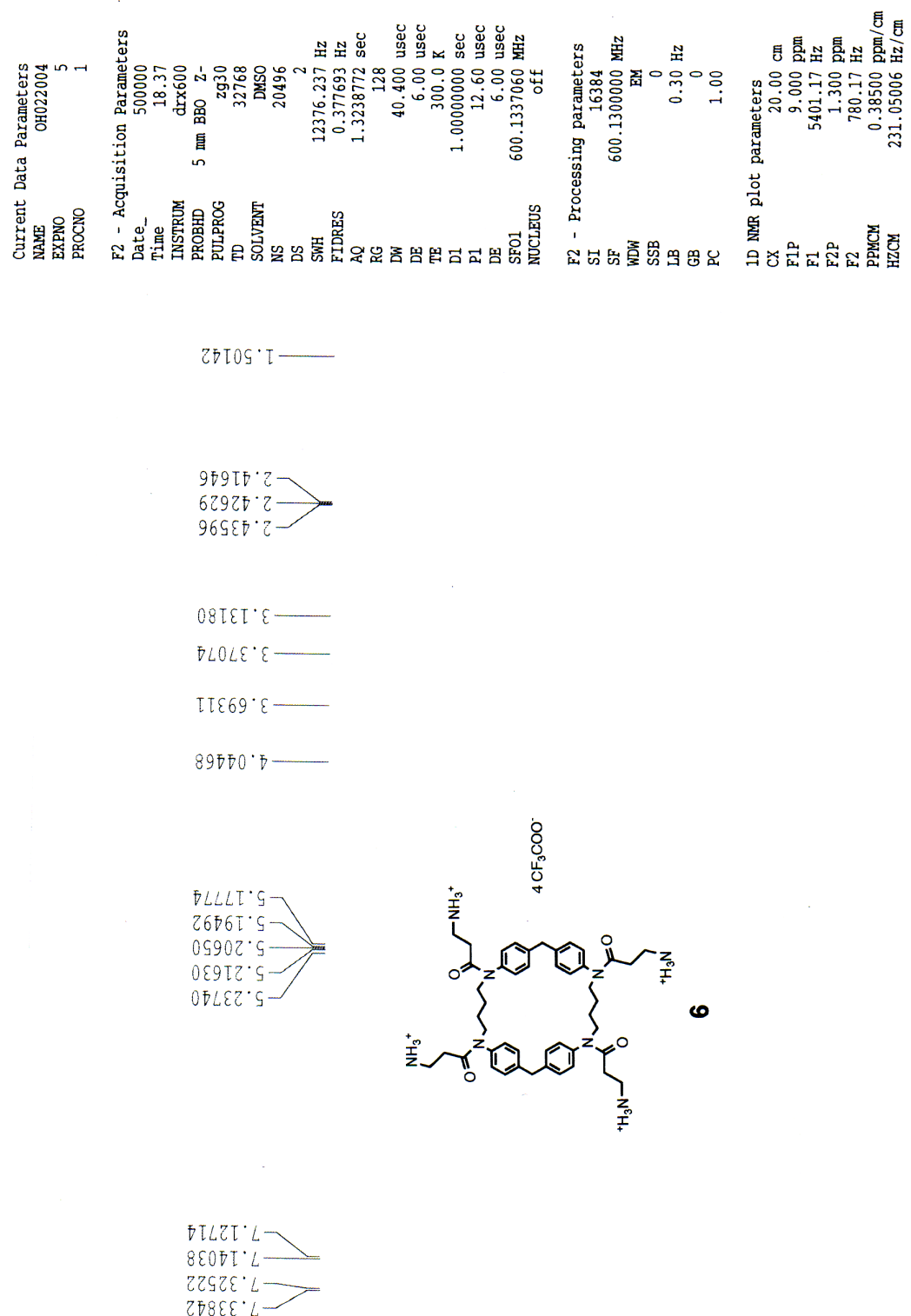

wdd

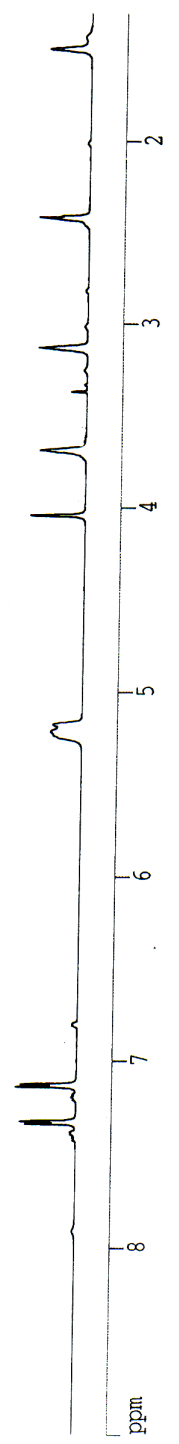

Figure 10. ${ }^{1} \mathrm{H}$ NMR spectrum of compound 6 

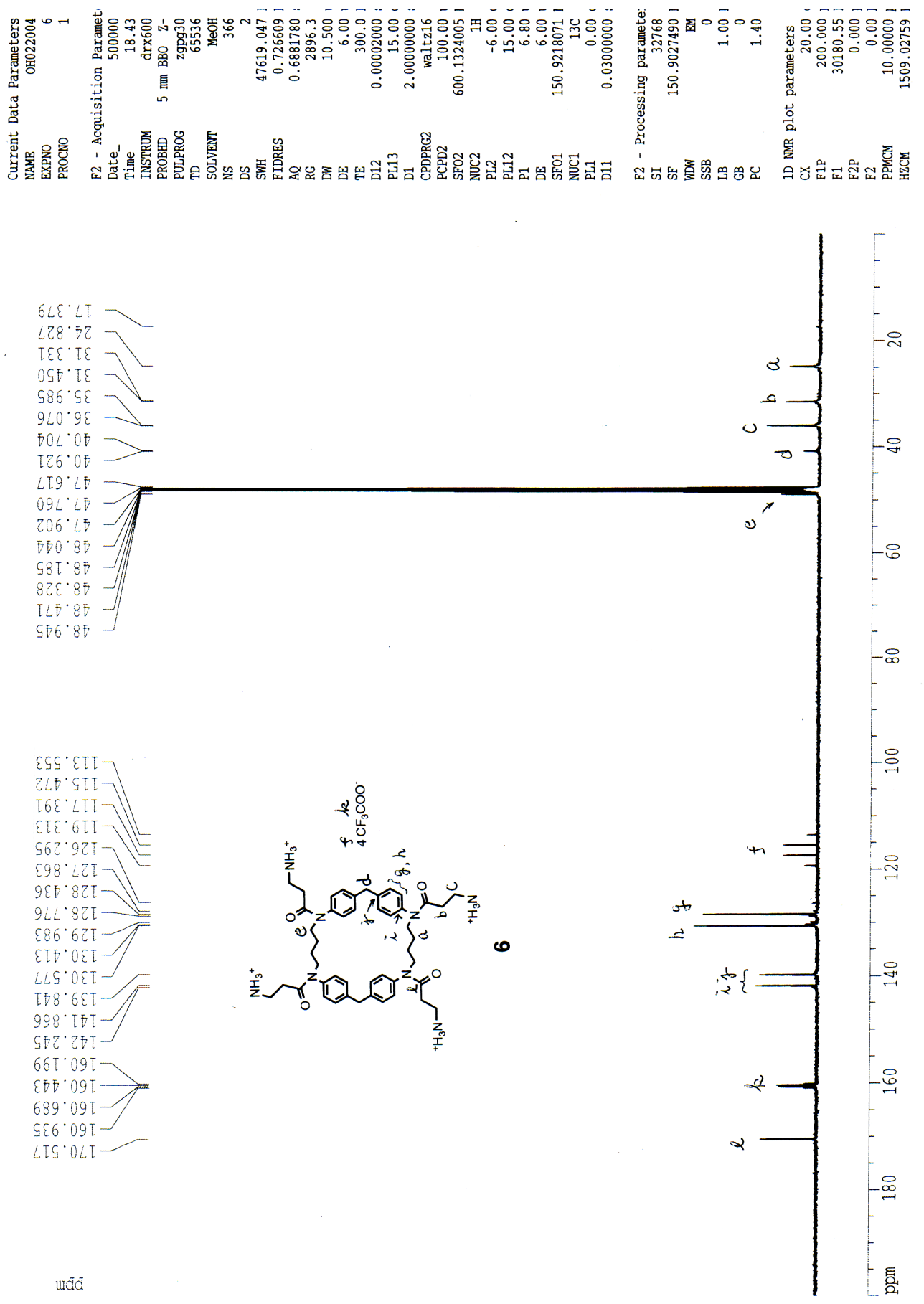

Figure 11. ${ }^{13} \mathrm{C}$ NMR spectrum of compound 6 